\title{
Rapid and Slow Chemical Synaptic Interactions of Cholinergic Projection Neurons and GABAergic Local Interneurons in the Insect Antennal Lobe
}

\author{
Ben Warren and Peter Kloppenburg \\ Biocenter, Institute for Zoology, and Cologne Excellence Cluster on Cellular Stress Responses in Aging-Associated Diseases (CECAD), University of Cologne, \\ 50674 Cologne, Germany
}

\begin{abstract}
The antennal lobe $(\mathrm{AL})$ of insects constitutes the first synaptic relay and processing center of olfactory information, received from olfactory sensory neurons located on the antennae. Complex synaptic connectivity between olfactory neurons of the AL ultimately determines the spatial and temporal tuning profile of (output) projection neurons to odors. Here we used paired whole-cell patch-clamp recordings in the cockroach Periplaneta americana to characterize synaptic interactions between cholinergic uniglomerular projection neurons (uPNs) and GABAergic local interneurons (LNs), both of which are key components of the insect olfactory system. We found rapid, strong excitatory synaptic connections between uPNs and LNs. This rapid excitatory transmission was blocked by the nicotinic acetylcholine receptor blocker mecamylamine. IPSPs, elicited by synaptic input from a presynaptic LN, were recorded in both uPNs and LNs. IPSPs were composed of both slow, sustained components and fast, transient components which were coincident with presynaptic action potentials. The fast IPSPs were blocked by the $\mathrm{GABA}_{\mathrm{A}}$ receptor chloride channel blocker picrotoxin, whereas the slow sustained IPSPs were blocked by the $\mathrm{GABA}_{\mathrm{B}}$ receptor blocker CGP-54626. This is the first study to directly show the predicted dual fast-and slow-inhibitory action of LNs, which was predicted to be key in shaping complex odor responses in the AL of insects. We also provide the first direct characterization of rapid postsynaptic potentials coincident with presynaptic spikes between olfactory processing neurons in the AL.
\end{abstract}

Key words: acetylcholine; antennal lobe; GABA; local interneuron; olfaction; projection neuron

\section{Introduction}

The first synaptic processing of olfactory signals is performed by similar mechanisms in the antennal lobe of insects and in the olfactory bulb of vertebrates. In both systems, local inhibitory and excitatory interactions between the glomerular pathways help to structure the spatial and temporal representation of olfactory information. In the antennal lobe (AL) these interactions are mediated by a functionally and morphologically diverse population of local interneurons (LNs), before projection neurons (PNs) relay the integrated olfactory information to the protocerebrum (for review, see Boeckh and Tolbert, 1993; Hildebrand and Shepherd, 1997; Hansson and Anton, 2000; Wilson and Mainen, 2006). This knowledge about the AL circuitry and its function is based on studies that used various experimental approaches such as electron microscopy, immunohistochemistry,

\footnotetext{
Received Feb. 24, 2014; revised July 16, 2014; accepted Aug. 11, 2014.

Author contributions: B.W. and P.K. designed research; B.W. performed research; B.W. and P.K. analyzed data; B.W. and P.K. wrote the paper.

This work was supported by an Alexander von Humboldt fellowship awarded to B.W. Work in the Kloppenburg laboratory was supported by Grants KL 762/5-1 and KL 762/6-1 from the Deutsche Forschungsgemeinschaft to P.K. We thank Helmut Wratil for excellent technical assistance, Debora Fusca for advice regarding image processing, and members of the Kloppenburg laboratory for fruitful discussions.

The authors declare that they have no conflict of interest.

Correspondence should be addressed to Peter Kloppenburg, Biocenter, University of Cologne, Zülpicher Strasse 47b, 50674 Cologne, Germany. E-mail: peter.kloppenburg@uni-koeln.de.

DOI:10.1523/JNEUROSCI.0765-14.2014

Copyright $\odot 2014$ the authors $\quad 0270-6474 / 14 / 3413039-08 \$ 15.00 / 0$
}

pharmacology, electrophysiology, optical imaging, genetics, and behavioral studies. Together these studies provided important insights into the structure and function of the insect olfactory system, including its synaptic connectivity. However, studies that investigated the functionality of synaptic connections between identified AL neurons directly and systematically by using paired recordings are sparse. A successful example for this approach is the analysis of excitatory synaptic connections between LNs and PNs, showing that lateral excitation in the AL can be mediated by electrical transmission (Huang et al., 2010; Yaksi and Wilson, 2010). Such studies are essential to reveal and analyze the physiological properties of synaptic connections in the AL circuitry, which are critical to understand the cellular mechanisms of olfactory information processing.

Previous studies in fruit fly and locust suggest that in the insect antennal lobe the inhibitory effect of GABAergic LNs during olfactory information processing can be caused by both rapid, transient and slow, sustained inhibitory synaptic transmission that is mediated by ionotropic $\mathrm{GABA}_{\mathrm{A}}$ and metabotropic $\mathrm{GABA}_{\mathrm{B}}$ receptors, respectively (MacLeod and Laurent, 1996; Wilson et al., 2004; Wilson and Laurent, 2005; Olsen and Wilson, 2008). Computational models that are based on these studies suggest that $\mathrm{GABA}_{\mathrm{B}}$ receptor-mediated slow, sustained inhibition is key in producing reliable and distinct responses to odors, whereas $\mathrm{GABA}_{\mathrm{A}}$ receptor-mediated fast inhibition is key in synchronizing PN output (Bazhenov et al., 2001a,b; Assisi et al., 2012). However, whereas syn- 
aptic connections between cholinergic uniglomerular PNs (uPNs) and GABAergic LNs have been confirmed by paired whole-cell patch-clamp recordings (Huang et al., 2010; Yaksi and Wilson, 2010; Liu and Wilson, 2013), dual rapid, transient and slow, sustained transmission between these neurons has not been analyzed systematically. Here we used paired patch-clamp recordings to investigate in detail the physiology of synapses between excitatory cholinergic uPNs and inhibitory GABAergic LNs, and between pairs of GABAergic LNs. The study was conducted in the AL of the cockroach Periplaneta americana. In P. americana the physiology of the central olfactory neurons (Ernst and Boeckh, 1983; Lemon and Getz, 1997, 1998, 2000; Strausfeld and Li, 1999; Husch et al., 2009a,b; Pippow et al., 2009) and the circuitry of the olfactory system have been analyzed in great detail down to the biochemical, structural, and ultrastructural level (Distler, 1989, 1990; Malun, 1991a,b; Malun et al., 1993; Distler and Boeckh, 1997a,b; Distler et al., 1998; Neupert et al., 2012; Fusca et al. 2013).

\section{Materials and Methods}

Animals and materials. P. americana were reared in crowded colonies at $27^{\circ} \mathrm{C}$ under a $13 / 11 \mathrm{~h}$ light/dark photoperiod regimen on oats and rabbit food. The experiments were performed with adult males. All chemicals, unless otherwise stated, were obtained from Sigma-Aldrich and AppliChem in "pro analysis" purity grade.

Intact brain preparation. The intact brain preparation was mainly based on an approach described previously (Husch et al., 2009a,b). The animals were anesthetized by $\mathrm{CO}_{2}$ and placed in a custom-built holder, and the head was immobilized with tape (Tesa Extrapower Gewebeband). The head capsule was opened by cutting a window between the two compound eyes at the bases of the antennae. The brain was dissected from the head capsule in extracellular saline (composition is given below) and pinned in a Sylgard-coated (Dow Corning) recording chamber. To gain access to the recording site and facilitate the penetration of pharmacological agents into the tissue, we desheathed the brain using fine forceps. Preparations were enzyme treated with a mixture of collagenase (8 U/ml, LS004194, Worthington) and dispase $(0.7 \mathrm{U} / \mathrm{ml}$, LS02100, Worthington) dissolved in normal extracellular saline $[\sim 1$ min, room temperature (RT)]. For the recordings, the somata of the $\mathrm{AL}$ neurons were visualized with a fixed-stage upright microscope (BX51WI, Olympus) using a water-immersion objective (UMPLFL, 40×, $0.8 \mathrm{nu}-$ merical aperture, $3.3 \mathrm{~mm}$ working distance, Olympus) and infrared differential interference contrast optics (Dodt and Zieglgänsberger, 1994).

Whole-cell recordings. Whole-cell recordings were performed at $24^{\circ} \mathrm{C}$ following the methods described by Hamill et al. (1981). Electrodes with tip resistances between 2 and $4 \mathrm{M} \Omega$ were fashioned from borosilicate glass (0.86 mm inner diameter, $1.5 \mathrm{~mm}$ outer diameter; GB150-8P, Science Products $\mathrm{GmbH}$ ) with a vertical pipette puller (PP-830 or PC-10, Narishige). Recording pipettes were filled with intracellular saline containing the following (in mM): $190 \mathrm{~K}$-aspartate, $10 \mathrm{NaCl}, 1 \mathrm{CaCl}_{2}, 2$ $\mathrm{MgCl}_{2}, 10$ HEPES, 10 EGTA, and adjusted to $\mathrm{pH} 7.2$ with $\mathrm{KOH}$, resulting in an osmolarity of $\sim 415 \mathrm{mOsm}$. To make GABAergic LNs electrotonically more compact (for PN-to-LN pairs only), $20 \mathrm{~mm}$ tetraethylammonium (TEA) was added to the pipette solution to block $\mathrm{K}^{+}$channels. To compensate the osmolarity the $\mathrm{K}$-aspartate concentration was reduced to $170 \mathrm{~mm}$. To stain the neurons $0.1 \%$ Alexa Fluor 488 hydrazide and $0.1 \%$ Alexa Fluor 633 hydrazide (A10436 and A30634, Molecular Probes, Invitrogen) was dissolved in intracellular saline.

During the experiments, the cells were superfused constantly with normal extracellular saline containing the following (in $\mathrm{mM}$ ): $185 \mathrm{NaCl}, 4$ $\mathrm{KCl}, 6 \mathrm{CaCl}_{2}, 2 \mathrm{MgCl}_{2}, 10 \mathrm{HEPES}$, and $35 \mathrm{D}$-glucose. The solution was adjusted to $\mathrm{pH} 7.2$ with $\mathrm{NaOH}$ and to $430 \mathrm{mOsm}$ with glucose. To block $\mathrm{GABA}_{\mathrm{A}}, \mathrm{GABA}_{\mathrm{B}}$ receptors, or cholinergic excitatory receptors, $1 \mathrm{~mm}$ picrotoxin (PTX) (P1675, Sigma-Aldrich), $5 \mu \mathrm{M}$ CGP-54626 hydrochloride (BN0597, Biotrend), or $100 \mu \mathrm{M}$ mecamylamine hydrochloride (M9020, Sigma-Aldrich), respectively, were dissolved in extracellular saline. Blocking solutions were bath applied for at least $15 \mathrm{~min}$. Washout of these blockers with extracellular saline was performed for at least $20 \mathrm{~min}$.

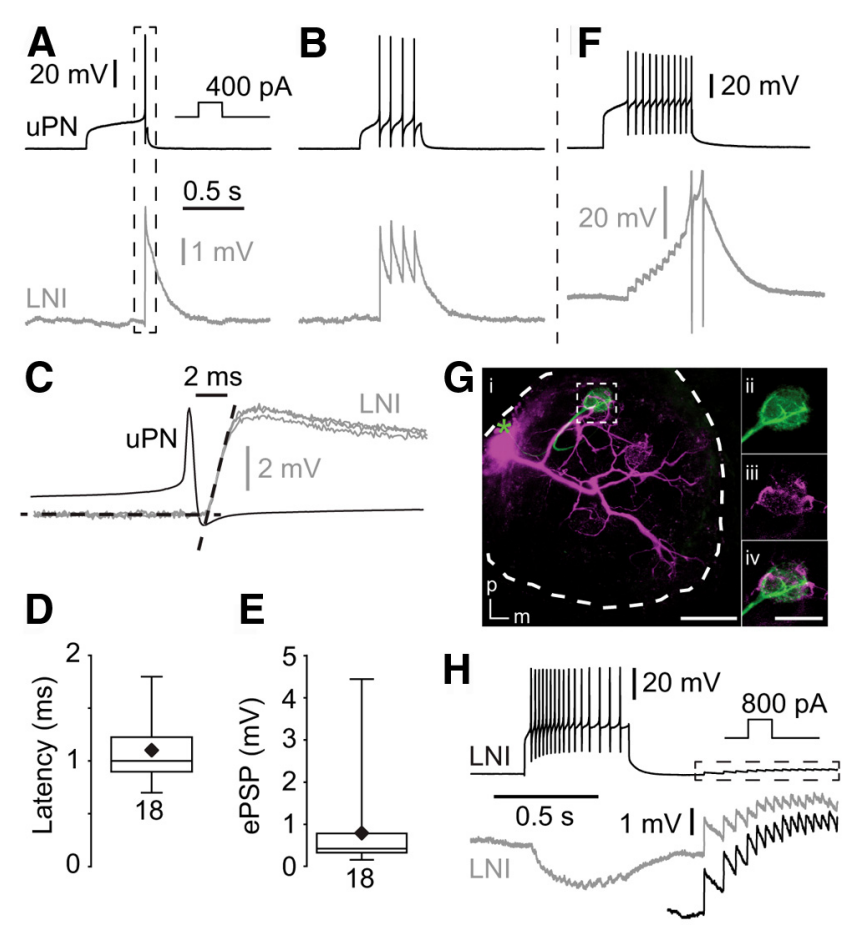

Figure 1. Type I LNs receive fast, excitatory input from uPNs. $A, B$, Single presynaptic action potentials in the uPN induced fast, transient short-latency EPSPs in the postsynaptic type I LN.C, Higher magnification of the frame in $\boldsymbol{A}$ showing fast synaptic input, with two additional fast EPSPs from the same neuron. The black dotted lines represent linear fits of the resting membrane potential and the rising phase of an EPSP. Their point of intersection was defined as the onset of the EPSP. D, Latency between the uPN spikes and EPSP in type I LNs. E, EPSP amplitudes in type I LNs that were elicited by single uPN action potentials. $F$, During high-frequency trains of action potentials the fast EPSPs can reach the action potential threshold (action potentials clipped). Gi, Morphology of the recorded uPN (green) and type I LN (magenta) revealed by staining of each neuron via the recording pipette. The green asterisk marks the position of the uPN soma that was lost during processing. Scale bar, $100 \mu \mathrm{m}$. ii-iv, Higher magnification of frame $i$ showing neurites of both neurons in the same glomerulus. $m$, Medial; $p$, posterior. Scale bar, $50 \mu \mathrm{m}$. $\boldsymbol{H}$, Recording from two type I LNs showing coincident EPSPs presumably due to dyadic input from a uPN. The black trace in the dotted box is enlarged underneath.

Whole-cell voltage- and current-clamp recordings were performed with an EPC10 patch-clamp amplifier (HEKA-Elektronik) controlled by the program Patchmaster (version 8.63, HEKA-Elektronik) running under Windows. Electrophysiological data were typically sampled at 20 $\mathrm{kHz}$. Voltage-clamp recordings were low-pass filtered at $2 \mathrm{kHz}$ with a four-pole Bessel filter and current-clamp recordings used a $10 \mathrm{kHz}$ lowpass Bessel filter. Synaptic latency was defined as the time interval between the peak of the presynaptic action potential and the onset of the PSP. Onset of the PSP was defined as the point of intersection between the linear fits of the resting membrane potential and the rising phase of the PSP as demonstrated in Figure $1 C$ by black dotted lines. For figure clarity, data were additionally filtered offline in Igor (Igor Pro 6, Wavemetrics) with a $500 \mathrm{~Hz}$ low-pass filter. Compensation of the offset potential and capacitive currents was performed using the "automatic mode" of the EPC10 amplifier. The calculated liquid junction potential between intracellular and extracellular solution was also compensated $(15.6 \mathrm{mV}$ for normal and $13.4 \mathrm{mV}$ for $20 \mathrm{~mm}$ TEA intracellular saline; calculated with Patcher'sPowerTools plug-in from http://www3.mpibpc.mpg.de/groups/neher/ index.php?page $=$ aboutppt for Igor Pro 6). Series resistance $\left(R_{\mathrm{S}}\right)$ was compensated between 30 and $65 \%$ with a time constant of $100 \mu \mathrm{s}$.

Slide preparation and confocal microscopy. Directly after recordings, brains were fixed in Roti-Histofix (P0873, Carl Roth) for $30 \mathrm{~min}$ at RT. Subsequently, the brains were rinsed 5 times in $0.1 \mathrm{M}$ PBS before being dehydrated in an ethanol series and then cleared in methyl salicylate.

Fluorescence images were captured with a confocal microscope (LSM 510, Carl Zeiss) equipped with Plan-Apochromat $10 \times$ (numerical aper- 

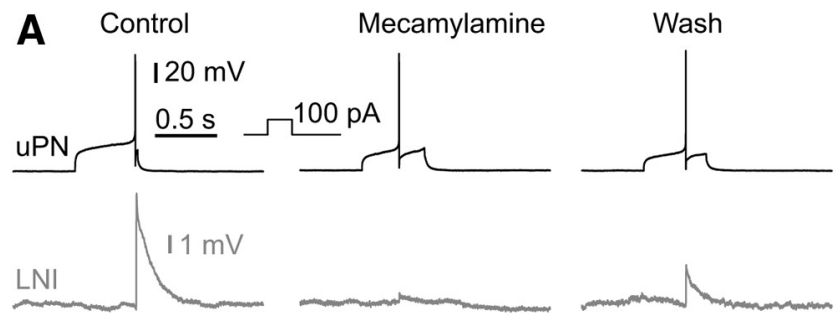

Figure 2. Fast excitatory synaptic transmission between uPNs and type I LNs was reversibly blocked by the nicotinic acetylcholine receptor blocker mecamylamine. $\boldsymbol{A}$, Example of a fast excitatory connection between a uPN and a type I LN that is reversibly blocked by $100 \mu \mathrm{m}$ mecamylamine. $\boldsymbol{B}$, Quantification of the effect of $100 \mu \mathrm{m}$ mecamylamine on the normalized EPSP amplitude.

ture 0.45 ) and $20 \times$ (numerical aperture 0.75 ) lenses. Using the multitrack mode, Alexa 633 and 488 were excited at 633 and $488 \mathrm{~nm}$, respectively. Fluorescence emission of Alexa 633 or Alexa 488 was collected through a $650 \mathrm{~nm}$ long-pass and a 505-530 nm bandpass filter, respectively. Confocal images were adjusted for contrast and brightness, overlaid, and stacked in ImageJ (version 1.47, National Institutes of Health). In the text and for bar graphs data are presented as mean \pm SD. For box plots the mean is represented by a black diamand and the median is represented by a horizontal line. When comparing significance between two groups of data a paired two-tailed $t$ test was used, when comparing three groups of data ANOVA was used with a Tukey's post-hoc test. Statistical significance was accepted when the $p$-value was $<0.05$. Statistical significance is represented by one, two, or three asterisks displayed between groups of data in the figures, which represent a $p$-value $<0.05,<0.01$, and $<0.001$, respectively.

\section{Results}

Here we used paired whole-cell patch-clamp recordings to study synaptic interactions between cholinergic uPNs and GABAergic LNs (which are named type I LNs in P. americana by Husch et al., 2009a,b) or between pairs of GABAergic type I LNs. Regarding their cellular properties, both neuron types form relative homogenous populations (Husch et al. 2009a,b). PSPs were elicited by stimulating the presynaptic neurons using current- or voltageclamp protocols, sometimes in conjunction with pharmacological blockers to characterize candidate transmitter receptors. An important goal of this study was to detect rapid, transient excitatory potentials and IPSPs that were mediated by spike-evoked monosynaptic transmission.

\section{Connections between uniglomerular projection neurons and type I local interneurons \\ Excitatory connections between $u P N$ s and type I LNs}

In paired current-clamp recordings single action potentials and trains of action potentials were elicited in uPNs by depolarizing current steps. Overall, we performed 112 double recordings from uPN and type I LN pairs, from which we found 62 to be synaptically connected. This relatively small number of connected pairs was not surprising since the recorded PNs were uniglomerular and the type I LNs were multiglomerular, innervating many but not all glomeruli (Husch et al., 2009a). Coincident to single presynaptic action potentials in uPNs, fast, transient, short-latency EPSPs could be recorded in the type I LNs (Fig. $1 A, B$ ). The latency from the peak of the spike in uPNs to the EPSP onset in type I LNs was short $(1.1 \pm 0.3 \mathrm{~ms}, n=18$; Fig. $1 C, D)$. The average amplitude of single action potential-evoked EPSPs in type I LNs was $0.8 \pm 1.0 \mathrm{mV}(n=18$; Fig. $1 E)$. During high-frequency trains of action potentials, these transient EPSPs can sum up and even reach the action potential threshold (Fig. $1 F$ ). Labeling of uPNtype I LN pairs revealed neurites of both neurons in the same glomerulus in which synapses between both neurons were pre-

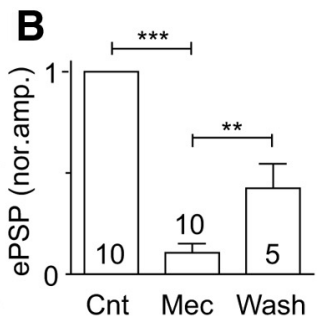

sumably located (Fig. $1 G$ ). In pairs of type I LNs we sometimes observed simultaneous rapid EPSPs (Fig. $1 H$ ), which most likely reflected excitatory input from a dyadic synapse of a uPN onto two type I LNs. We never observed depolarization of the postsynaptic type I LN, upon depolarization of the presynaptic uPN, before spikes were elicited in the $\mathrm{UPN}$, as was found for electrical synapses between AL neurons in Drosophila (Huang et al., 2010). Accordingly, we observed no hyperpolarization of the postsynaptic type I LN when the presynaptic uPN was hyperpolarized. In agreement with previous immunohistochemical and physiological studies, which suggested that uPNs are mostly cholinergic (Waldrop and Hildebrand, 1989; Homberg et al., 1995; Bicker, 1999; Homberg, 2002; Wilson et al., 2004; Fusca et al., 2013; Liu and Wilson, 2013), the excitatory synaptic transmission between uPNs and type I LNs could be reversibly blocked by the nicotinic acetylcholine receptor blocker mecamylamine (Fig. 2).

\section{Inhibitory connection between type I LNs and $u P N s$}

Since the strong depolarizing current injections that we used to drive the presynaptic LNs often caused "unstable" membrane potentials after the current pulses, we depolarized the presynaptic LN under voltage clamp. By depolarizing the membrane potential under voltage clamp with voltage steps or voltage ramps to $\sim+50 \mathrm{mV}$, we reliably detected IPSPs in the postsynaptic uPN (Fig. $3 A-F$ ). From the 62 connected pairs (uPN $\rightarrow$ type I LN) we tested 32 pairs for reciprocity. In $\sim 90 \%$ of the tested pairs the synaptic connections were reciprocal with uPNs and type I LNs eliciting excitatory and inhibitory PSPs, respectively. The IPSPs in the uPNs consisted in all experiments of a slow, sustained component, that we termed sustained IPSP. Application of large, hyperpolarizing voltage pulses in the presynaptic LN did not cause membrane potential changes in the postsynaptic uPN, which provided no evidence for electrical synapses between type I LNs and uPNs (Fig. 3G). In $\sim 20 \%$ (6 of 32) of synaptically connected pairs, unclamped action potentials in the presynaptic type I LN elicited reliably coincident rapid IPSPs in the postsynaptic uPN, which we termed fast IPSPs (Fig. $3 B, C$ ). The latency of these fast IPSPs was $2.2 \pm 1.3 \mathrm{~ms}(n=6$; Fig. $3 C, D)$. The average amplitude of the fast IPSPs was $223 \pm 134 \mu \mathrm{V}(n=6$; Fig. $3 E)$ immediately after establishing the recording. Within a few minutes the fast IPSPs showed a significant rundown making it difficult to systematically characterize the pharmacology of these potentials. However, Figure $3 F$ shows an example with robust and stable fast IPSPs which were rapidly blocked when 1 mM PTX was applied.

To determine the reversal potential of the sustained IPSPs we voltage-clamped the postsynaptic uPN to membrane potentials between $-120 \mathrm{mV}$ and $-70 \mathrm{mV}$ during stimulation of the presynaptic type I LN with $+50 \mathrm{mV}$ voltage steps. However, reliable measurements are only possible from paired recordings with strong connectivity and sufficient voltage control. Figure 4 shows such an example with particularly good voltage control and large synaptic currents. The reversal potential of the sustained IPSP was $\sim-110 \mathrm{mV}$ (Fig. 4), which is near the calculated reversal potential for $\mathrm{K}^{+}(-99 \mathrm{mV})$, suggesting that the slow, sustained IPSP was mostly $\mathrm{K}^{+}$dependent. This result, together with the slow, sustained time course of the IPSPs, indicated that sustained IPSPs might be mediated by metabotropic $\mathrm{GABA}_{\mathrm{B}}$ receptors (Fig. 
A

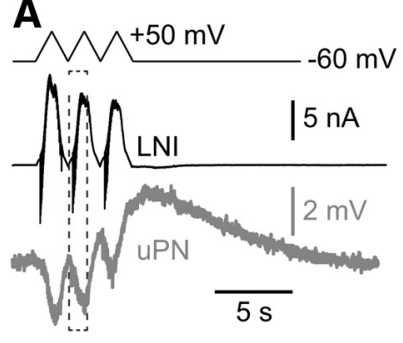

C

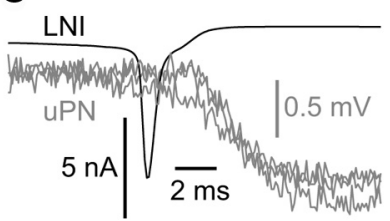

$\mathbf{F}$

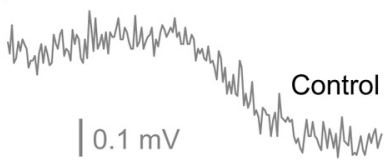

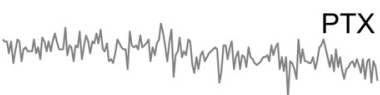

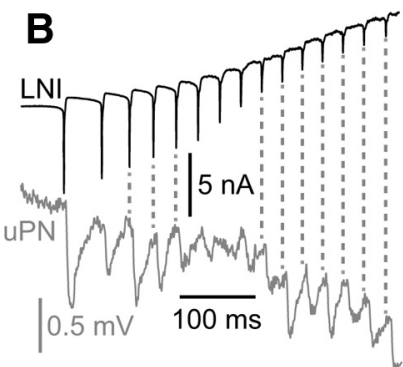

D $\quad E$
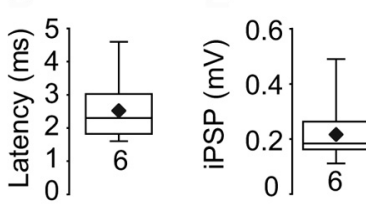

G

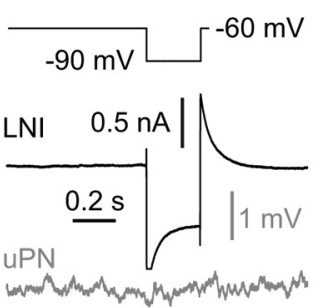

A
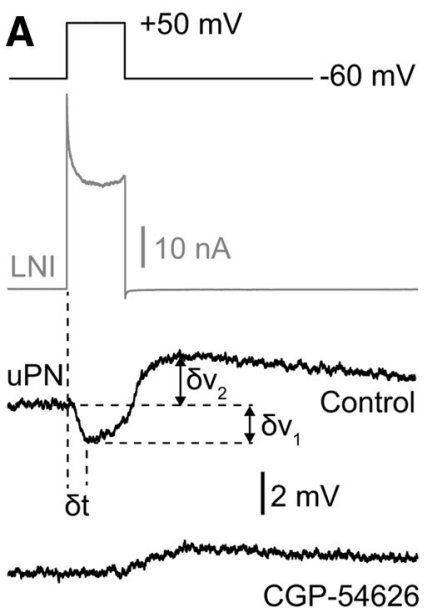

B

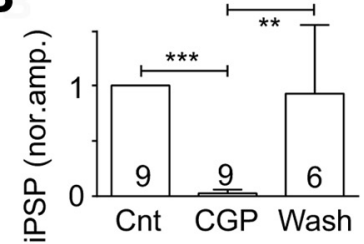

C

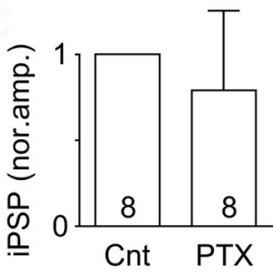

Figure 3. uPNs receive fast action potential-evoked inhibitory input from type I LNs. $\boldsymbol{A}-\boldsymbol{C}$, Presynaptic depolarization in the type I LNs induced IPSPs in the UPN. The IPSPs consisted of a sustained component $(\boldsymbol{A})$ and fast, transient components that were coincident with presynaptic action potentials ( $\boldsymbol{B}, \boldsymbol{C}$. $\boldsymbol{B}$ is a higher magnification of the frame in $\boldsymbol{A}$. $\boldsymbol{C}$ shows an overlay of three fast IPSPS in the same uPN that were evoked by single presynaptic action potentials. $\boldsymbol{D}$, Latency between the presynaptic LN action potentials and the IPSPs in the uPNs. $\boldsymbol{E}$, Amplitude of fast IPSPs in uPNs. $\boldsymbol{F}$, The fast inhibitory synaptic transmission between type I LNs and uPNs was abolished by PTX, a blocker of the $G_{A B A}$ receptor chloride channels (each trace is an average of 5). G, Hyperpolarization of type I LNs had no effect on the membrane potential of the postsynaptic uPN.
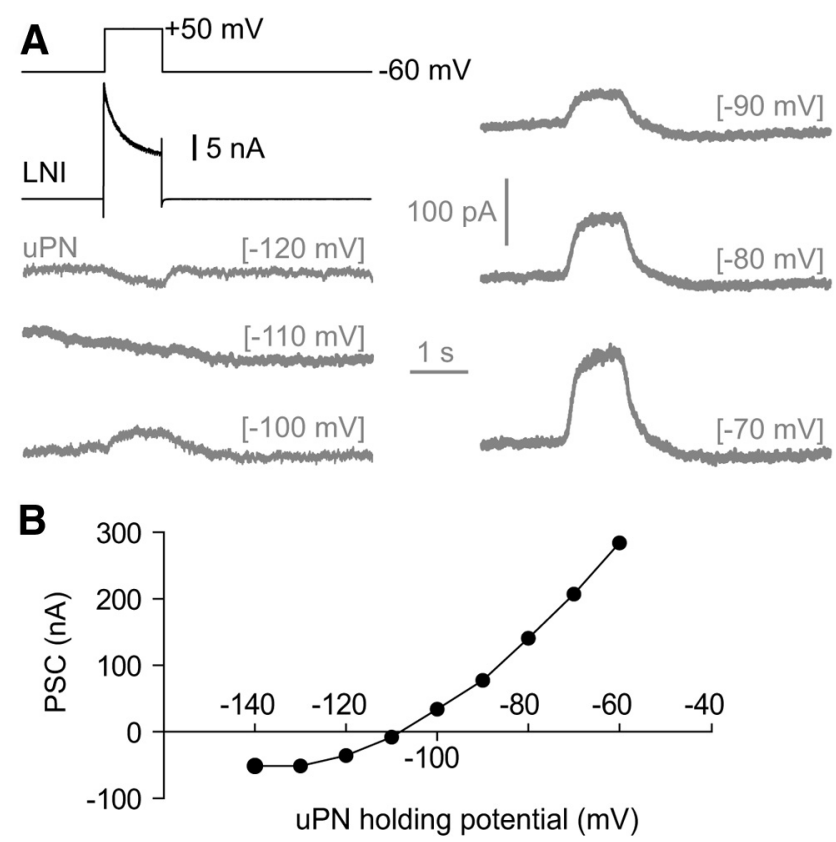

Figure 4. The reversal potential of the sustained IPSCs in uPNs. A, Black trace, Whole-cell current of the presynaptic type I LN induced by a voltage step to $+50 \mathrm{mV}$. Gray traces, Resulting currents in the postsynaptic uPN that was clamped at different holding potentials which are given in brackets. $B, I-V$ plot showing the reversal potential of the sustained IPSC.

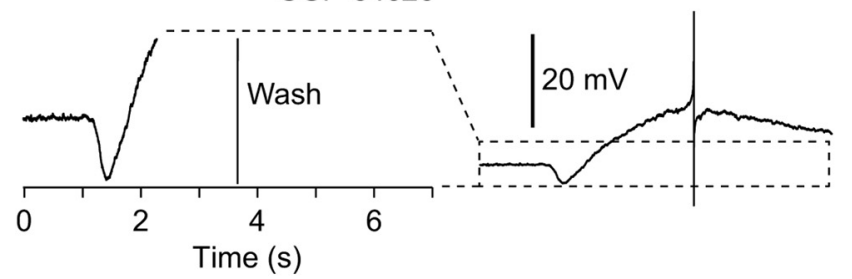

D

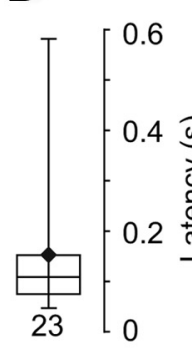

E

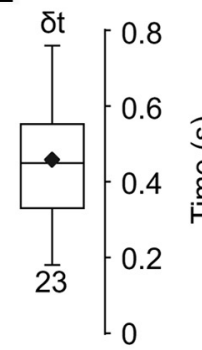

$\mathbf{F}$

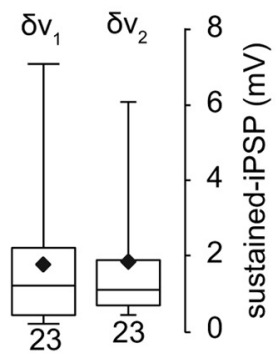

Figure 5. The slow inhibitory synaptic transmission between type I LNs and uPNs was reversibly blocked by the $\mathrm{GABA}_{\mathrm{B}}$ receptor blocker (GP-54626. $A$, Example of a sustained inhibitory connection between a type I LN and a uPN that was reversibly blocked by $5 \mu \mathrm{m}$ CGP-54626. Note the slow depolarization that followed the sustained IPSPS, which increased during the wash. The wash trace is shown on the left in the same scale as the control and the CGP trace (large depolarization and action potential are clipped). To the right the same wash trace is shown in lower magnification to provide a better overview. B, Quantification of the CGP-54626 effect on the normalized sustained IPSP amplitude. C, PTX, a blocker of the $G A B A_{A}$ receptor chloride channels, had no effect on the sustained inhibitory transmission. $\boldsymbol{D}$, Latency of the sustained IPSPs. $\boldsymbol{E}$, Time from start of the voltage step to maximum IPSP, as depicted in $\boldsymbol{A}$. $\boldsymbol{F}$, The amplitude of the sustained IPSP $\left(\delta v_{1}\right)$ and the slow depolarization $\left(\delta v_{2}\right)$, as depicted in $\boldsymbol{A}$.

$5 A-F)$. In agreement with this notion, we found that the $\mathrm{GABA}_{\mathrm{B}}$ receptor blocker CGP-54626 (5 $\mu \mathrm{M})$ completely blocked the slow, sustained IPSPs (Fig. 5A,B). This effect was reversible upon washout. The $\mathrm{GABA}_{\mathrm{A}}$ receptor blocker PTX (1 mM) had no significant effect on the slow, sustained IPSPs in uPNs (Fig. 5C). After the slow, sustained IPSPs we regularly observed a delayed slow depolarization (Figs. 3A, 5A). This depolarization lasted several seconds and occasionally reached the action potential threshold (Fig. 5A). Parameters of the sustained IPSPs are shown in Figure $5 D-F$.

\section{Connections between type I local interneurons}

All 18 recorded type I LN pairs were synaptically connected. We induced trains of action potentials in the presynaptic LN by depolarizing current steps, which reliably elicited IPSPs in the postsynaptic LN (Fig. 6A,B). Similar to IPSPs in uPNs, all IPSPs recorded in type I LNs had a slow, sustained component (sus- 

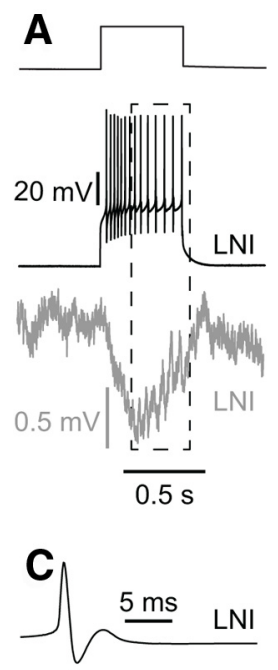

B

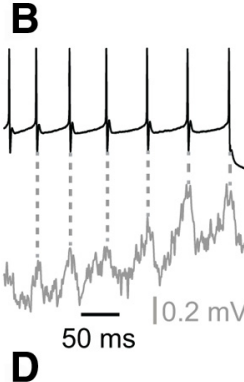

$\mathbf{F}$

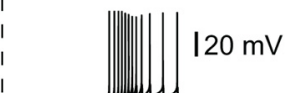

LNI$$
0.5 \mathrm{~s}
$$
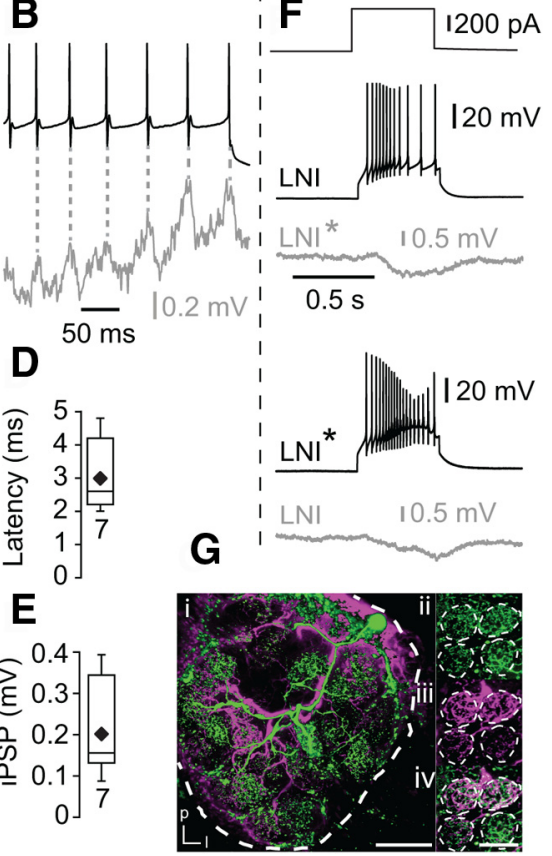

Figure 6. Inhibitory synaptic connections between pairs of type I LNs. A, B, Presynaptic trains of action potentials induced IPSPs in the postsynaptic type I LN. The IPSPs consisted of a sustained component $(\boldsymbol{A})$ and fast, transient components that were coincident with presynaptic action potentials ( $\boldsymbol{B}, \boldsymbol{C})$. $\boldsymbol{B}$ is a higher magnification of the frame in $\boldsymbol{A}$. $\boldsymbol{C}$, Three overlaid fast IPSPS that were evoked by presynaptic action potentials in the same postsynaptic LN. $\boldsymbol{D}$, Latency between the presynaptic action potential and fast IPSPs. $E$, Amplitude of fast IPSPs in type I LNs elicited by single action potentials in the presynaptic type I LNs. $\boldsymbol{F}$, Example of the reciprocal inhibitory connection between two type I LNs. Gi, Morphology of two simultaneously recorded type I LNs revealed by staining of each neuron via the recording pipette. Scale bar, $100 \mu \mathrm{m}$. ii-iv, Higher magnification of four glomeruli showing neurites of both LNs in the same glomeruli. I, lateral; p, posterior. Scale bar, $50 \mu \mathrm{m}$.

tained IPSPs) that was overlaid in $\sim 30 \%$ (7 of 18) of the recordings by fast IPSPs coincident with presynaptic action potentials. The latency from the peak of the action potential to the onset of the fast IPSPs was $3.0 \pm 1.0 \mathrm{~ms}(n=7$; Fig. $6 C, D)$. The magnitude of the fast IPSPs was $203 \pm 116 \mu \mathrm{V}(n=7$; Fig. $6 E)$, which is similar to the amplitude of the fast IPSPs observed in uPNs. In $\sim 95 \%$ of the connected type I LN pairs the connections were reciprocal (Fig. $6 F$ ). Labeling of type I LN pairs revealed glomeruli that were innervated by both LNs in which synapses between both neurons were presumably located (Fig. 6G).

It appeared likely that fast IPSPs were mediated by ionotropic $\mathrm{GABA}_{\mathrm{A}}$ receptors, and that the sustained IPSPs were mediated by $\mathrm{GABA}_{\mathrm{B}}$ receptors. In agreement with this, $1 \mathrm{~mm}$ PTX completely blocked fast IPSPs in type I LNs (Fig. $7 A, B$ ), and $5 \mu \mathrm{M}$ CGP54626 reduced the sustained IPSPs significantly (Fig. 7C,D), but had no significant effect on the fast IPSPs (Fig. $7 A, B$ ). However, we also found that $1 \mathrm{~mm}$ PTX reduced the sustained IPSPs significantly (Fig. $7 E, F)$.

\section{Discussion}

The current study investigated chemical synaptic interactions between GABAergic LNs (type I LNs) and cholinergic uPNs, and between pairs of GABAergic type I LNs in the AL of the cockroach, $P$. americana; both neuron types are key components in the AL circuitry. This is the first study in which the dynamic properties of synaptic connections, such as fast, ionotropic and slow, metabotropic modes of transmission, were directly analyzed by paired recordings. We consider such an analysis impor-
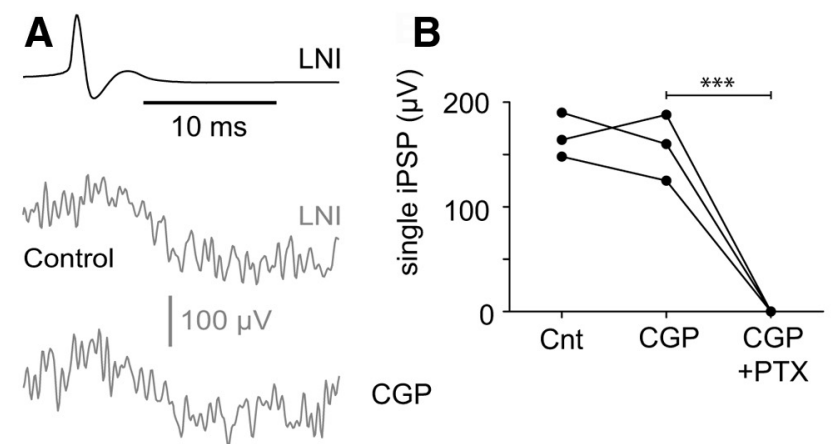

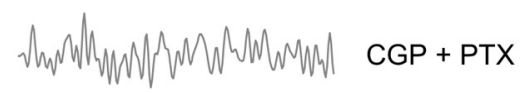
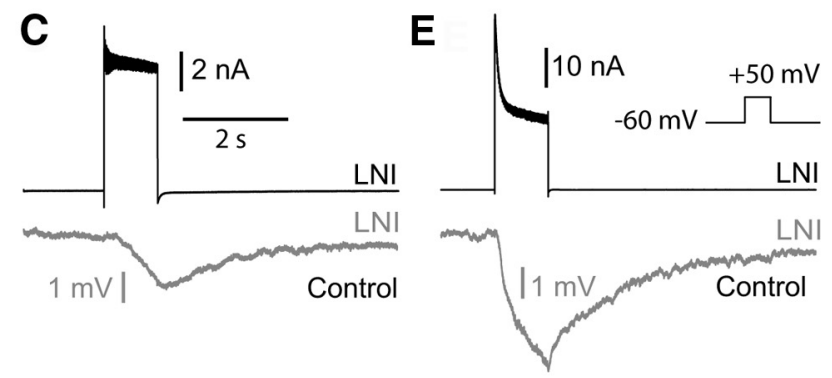

I $1 \mathrm{mV}$ CGP-54626
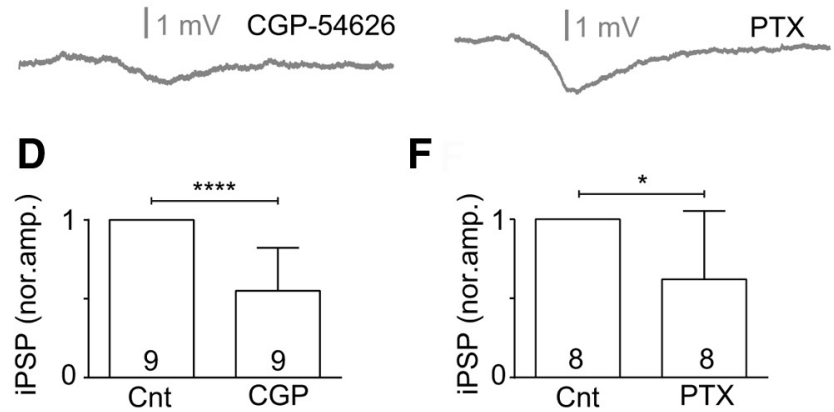

$\mathbf{F}$

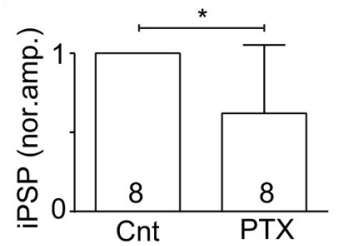

Figure 7. $\mathrm{GABA}_{\mathrm{A}}$ and $\mathrm{GABA}_{\mathrm{B}}$ receptor-mediated inhibition can contribute to inhibitory transmission between type I LNs during strong presynaptic depolarization. $\boldsymbol{A}, \boldsymbol{B}$, The fast single action potential-evoked inhibitory synaptic transmission between type I LNs was reversibly blocked by $1 \mathrm{mM}$ PTX, a blocker of the $\mathrm{GABA}_{\mathrm{A}}$ receptor chloride channels. The fast IPSPs were not affected by $5 \mu \mathrm{m}$ CGP-54626, a GABA ${ }_{B}$ receptor blocker. C-F, CGP-54626 (5 $\left.\mu \mathrm{m} ; \boldsymbol{C}, \boldsymbol{D}\right)$ and PTX (1 $\mathrm{mm} ; \boldsymbol{E}, \boldsymbol{F})$ decreased the sustained IPSPs that were evoked by strong presynaptic depolarization.

tant, since the network properties depend significantly on the dynamics of synaptic transmission (Bazhenov et al., 2001a,b). Between uPNs and type I LNs we found rapid, strong excitatory cholinergic synaptic transmission that was coincident with single presynaptic action potentials. Type I LNs provided inhibitory synaptic input to uPNs and other type I LNs. The IPSPs were composed of two components, fast IPSPs that were coincident with presynaptic action potentials and sustained IPSPs. The fast IPSPs were blocked by PTX, a blocker of the $\mathrm{GABA}_{\mathrm{A}}$ receptor chloride channels, whereas the sustained IPSPs were blocked by the $\mathrm{GABA}_{\mathrm{B}}$ receptor blocker CGP-54626. Furthermore, this is the first study that analyzed directly functional synaptic connections between GABAergic LNs.

Processing of olfactory information in the AL involves complex synaptic interactions, and previous work has established the functional relevance of inhibitory GABAergic and excitatory cholinergic interactions between AL neurons. In transmission electron microscopic studies an abundance of chemical synapses have been identified between inhibitory GABAergic LNs and the 
excitatory cholinergic uPNs and between LN pairs, which were predominately dyadic and sometimes reciprocal (Tolbert and Hildebrand, 1981; Distler, 1990; Malun, 1991a,b; Leitch and Laurent, 1996; Distler and Boeckh, 1997b; Distler et al., 1998). IPSCs in the $\mathrm{uPNs}$ can be mediated by ionotropic $\mathrm{GABA}_{\mathrm{A}}$ and metabotropic $\mathrm{GABA}_{\mathrm{B}}$ receptors (MacLeod and Laurent, 1996; Wilson and Laurent, 2005; Olsen and Wilson, 2008), and EPSPs in GABAergic LNs can be mediated by ionotropic acetylcholine receptors (Liu and Wilson, 2013), which suggested that synaptic transmission between AL neurons can have different dynamic properties.

MacLeod and Laurent (1996) demonstrated that application of the specific ionotropic $\mathrm{GABA}_{\mathrm{A}}$ blocker picrotoxin abolished fast inhibitory transmission between LNs and PNs, which desynchronized PNs. However, this treatment did not affect the slow patterning of $\mathrm{PN}$ odor responses. Computational models that were based on these studies provided a mechanistic framework to better understand how the dynamics of synaptic transmission between the excitatory PNs and inhibitory LNs, and between pairs of inhibitory LNs, shape the functional network properties during processing of olfactory information. Bazhenov et al. (2001a,b) showed, in detail, that fast transient reciprocal inhibitory/excitatory synapses between LNs and PNs and inhibitory synapses between LNs were pivotal for maintaining coherent network oscillations and creating transient synchrony of PN responses to odors. In this model the reciprocal inhibitory/excitatory connections between LNs and PNs are pivotal to generate and maintain oscillatory activity, whereas the inhibitory interactions between LNs determine the epochs of PN synchronization. Without inhibition between the LNs, the network generated sustained synchronization between PNs, which is in contrast to the transient synchrony of PNs that is generally observed in vivo (MacLeod and Laurent, 1996), and the network had a reduced ability to discriminate odors. Thus, inhibition between LNs seems to support complexity in the PN response and increased the network performance. In an associated study, Bazhenov et al. (2001b) showed that slow inhibition with decay time constants of a few hundred milliseconds can cause temporal patterning of the $\mathrm{PN}$ spike train during odor responses. The importance of LN-LN inhibition for odor discrimination has also been suggested in other modeling studies (Linster and Smith, 1997; Bazhenov et al., 2001a,b; Assisi et al., 2012; Capurro et al., 2012; Nowotny et al., 2013). In this context it is interesting that in our study, all inhibitory type I LN pairs were connected and 95\% of these connections were reciprocal, indicating a highly interconnected network. Since previous comprehensive analysis of insect AL LN types, like the one performed in Drosophila (Chou et al. 2010; Seki et al., 2010), revealed a high diversity of LN types with complex overlapping projection patterns, further investigations of LN-LN connectivity are crucial to foster realistic models of spatiotemporal processing of olfactory information. In any case, the general importance of LN-mediated inhibition to accomplish spatio- and/or temporal odor representation in the AL has already been found or suggested for other insects including bees (Linster and Smith, 1997; Sachse and Galizia, 2002; Linster et al., 2005; Deisig et al., 2010; Schmuker et al., 2011, 2014). Such inhibitory connections are also reflected in the complex odor responses of PNs with fast, transient and slow, sustained excitatory/ inhibitory response components. These multiphasic odor responses are associated with temporal coding schemes, which use early, fast response components to mediate a latency code to signal the presence and identity of an odor, whereas the later response pattern signifies a refined code of odor identity and concentration (Krofczik et al., 2009; Belmabrouk et al., 2011; Kuebler et al., 2011; Capurro et al., 2012; Brill et al., 2013).

Although these studies provided convincing experimental and theoretical evidence how the dynamics of synaptic transmission can shape the dynamical network properties, fast and slow PSP components have not been revealed or, rather differentiated by direct measurements. Although recent elegant and technically demanding paired recordings in the Drosophila AL indeed showed reciprocal excitatory/inhibitory connectivity between PNs and LNs, it has been difficult to resolve the dynamics of the synaptic transmission (Huang et al., 2010; Liu and Wilson, 2013). In paired $\mathrm{PN} \rightarrow \mathrm{LN}$ recordings the excitatory input was slow and only elicited in response to large current injection into the presynaptic uPN. Despite the slow time course, the EPSPs were completely abolished by mecamylamine, an antagonist of fast-acting nicotinic acetylcholine receptors.

Similarly, in paired $\mathrm{LN} \rightarrow \mathrm{PN}$ recordings the IPSPs had a slow time course (Liu et al., 2013), although both fast and slow IPSPs were hypothesized, since $\mathrm{GABA}_{\mathrm{A}}$ and $\mathrm{GABA}_{\mathrm{B}}$ receptor responses have been shown in Drosophila PNs (MacLeod and Laurent, 1996; Wilson and Laurent, 2005; Olsen and Wilson, 2008). A straightforward explanation for these observations is that PSPs that are evoked by single action potentials are small and difficult to detect given the electrotonically distal location of synaptic receptors relative to the recording site at the soma. Most likely only summated PSPs were large enough to be recorded from the somata.

Using electrotonically compact paired patch-clamp recordings, it is verified by our study that, at least for P. americana, fast cholinergic transmission between uPNs and LNs occurs. The short latency between the presynaptic action potential and the fast kinetics, and the fact that it can be completely blocked by mecamylamine clearly suggest that the EPSPs are mediated by nicotinic acetylcholine receptors. We could also show that between type I LNs and uPNs, and between pairs of type I LNs, fast and slow GABAergic transmission occurs. The kinetics of fast IPSPs and the fact that they were blocked by picrotoxin strongly indicate that they are mediated by ionotropic $\mathrm{GABA}_{\mathrm{A}}$ receptors. The time course of the sustained IPSPs, their reversal potential, and the finding that most of it can be blocked by CGP-54626 suggest that they are mostly mediated by metabotropic $\mathrm{GABA}_{\mathrm{B}}$ receptors. Note that the sustained IPSPs, especially when evoked by strong presynaptic depolarization, were also reduced by picrotoxin. A straightforward interpretation is that an ionotropic component contributes to the sustained IPSPs which cannot be resolved in discrete transient IPSPs during strong tonic depolarization and/or spike frequencies. After the sustained IPSPs we regularly observed a depolarization. Because the depolarization can be detected even after blocking the GABA-induced hyperpolarization, it cannot be explained by a voltage-dependent rebound effect or by a chloride-induced mechanism. Since we have evidence that GABAergic type I LNs can contain peptides (Neupert et al., 2012), release of a cotransmitter might induce the depolarization.

Collectively, our study provides a detailed analysis, including the time course, of synaptic connections between inhibitory GABAergic type I LNs and excitatory cholinergic uPNs, and pairs of type I LNs. We consider this experimental study an important contribution to the better understanding of how olfactory information is processed, since it verifies crucial hypotheses about synaptic transmission between AL neurons that form the base of the current computational models for olfactory information processing. 


\section{References}

Assisi C, Stopfer M, Bazhenov M (2012) Excitatory local interneurons enhance tuning of sensory information. PLoS Comput Biol 8:e1002563. CrossRef Medline

Bazhenov M, Stopfer M, Rabinovich M, Huerta R, Abarbanel HDI, Sejnowski TJ, Laurent G (2001a) Model of transient oscillatory synchronisation in the locust antennal lobe. Neuron 30:553-567. CrossRef Medline

Bazhenov M, Stopfer M, Rabinovich M, Abarbanel HDI, Sejnowski TJ, Laurent G (2001b) Model of cellular and network mechanisms for odor-evoked temporal patterning in the locust antennal lobe. Neuron 30:569-581. CrossRef Medline

Belmabrouk H, Nowotny T, Rospars JP, Martinez D (2011) Interaction of cellular and network mechanisms for efficient pheromone coding in moths. Proc Natl Acad Sci U S A 108:19790-19795. CrossRef Medline

Bicker G (1999) Histochemistry of classical neurotransmitters in antennal lobes and mushroom bodies of the honeybee. Microsc Res Tech 45:174183. CrossRef Medline

Boeckh J, Tolbert LP (1993) Synaptic organisation and development of the antennal lobe of insects. Microsc Rec Tech 24:260-280. CrossRef Medline

Brill MF, Rosenbaum T, Reus I, Kleineidam CJ, Nawrot MP, Rössler W (2013) Parallel processing via a dual olfactory pathway in the honeybee. J Neurosci 33:2443-2456. CrossRef Medline

Capurro A, Baroni F, Olsson SB, Kuebler LS, Karout S, Hansson BS, Pearce TC (2012) Non-linear blend coding in the moth antennal lobe emerges from random glomerular networks. Front Neuroeng 5:6. CrossRef Medline

Chou YH, Spletter ML, Yaksi E, Leong JC, Wilson RI, Luo L (2010) Diversity and wiring variability of olfactory local interneurons in the Drosophila antennal lobe. Nat Neurosci 13:439-449. CrossRef Medline

Deisig N, Giurfa M, Sandoz JC (2010) Antennal lobe processing increases separability of odor mixture representations in the honeybee. J Neurophysiol 103:2185-2194. CrossRef Medline

Distler P (1989) Histochemical demonstration of GABA-like immunoreactivity in cobalt labelled neuron individuals in the insect olfactory pathway. Histochemistry 91:245-249. CrossRef Medline

Distler P (1990) GABA-immunohistochemistry as a label for identifying types of local interneurons and their synaptic contacts in the antennal lobes of the American cockroach. Histochemistry 93:617-626. CrossRef Medline

Distler PG, Boeckh J (1997a) Synaptic connections between identified neuron types in the antennal lobe glomeruli of the cockroach, Periplaneta americana: I. Uniglomerular projection neurons. J Comp Neurol 378: 307-319. CrossRef Medline

Distler PG, Boeckh J (1997b) Synaptic connections between identified neuron types in the antennal lobe glomeruli of the cockroach, Periplaneta americana: II. Local multiglomerular interneurons. J Comp Neurol 383: 529-540. CrossRef Medline

Distler PG, Gruber C, Boeckh J (1998) Synaptic connections between GABA-immunoreactive neurons and uniglomerular projection neurons within the antennal lobe of the cockroach, Periplaneta americana. Synapse 29:1-13. CrossRef Medline

Dodt HU, Zieglgänsberger W (1994) Infrared videomicroscopy: a new look at neuronal structure and function. Trends Neurosci 17:453-458. CrossRef Medline

Ernst KD, Boeckh J (1983) A neuroanatomical study on the organization of the central antennal pathways in insects. III. Neuroanatomical characterization of physiologically defined response types of deutocerebral neurons in Periplaneta americana. Cell Tissue Res 229:1-22. Medline

Flanagan D, Mercer AR (1989) Morphology and response characteristics of neurones in the deutocerebrum of the brain in the honeybee Apis mellifera. J Comp Physiol 164:483-494. CrossRef

Fusca D, Husch A, Baumann A, Kloppenburg P (2013) Choline acetyltransferase-like immunoreactivity in a physiologically distinct sub-type of olfactory non-spiking local interneurons in the cockroach (Periplaneta americana). J Comp Neurol 521:3556-3569. CrossRef Medline

Galizia CG, Kimmerle B (2004) Physiological and morphological characterization of honeybee olfactory neurons combined electrophysiology, calcium imaging and confocal microscopy. J Comp Physiol A Neuroethol Sens Neural Behav Physiol 190:21-38. Medline

Hamill OP, Marty A, Neher E, Sakmann B, Sigworth FJ (1981) Improved patch-clamp techniques for high-resolution current recording from cells and cell-free membrane patches. Pflugers Arch 391:85-100. CrossRef Medline

Hansson BS, Anton S (2000) Function and morphology of the antennal lobe. Annu Rev Entomol 45:203-231. CrossRef Medline

Hildebrand JG, Shepherd GM (1997) Mechanism of olfactory discrimination: converging evidence for common principles across phyla. Annu Rev Neurosci 20:595-631. CrossRef Medline

Homberg U (2002) Neurotransmitters and neuropeptides in the brain of the locust. Microsc Res Tech 56:189-209. CrossRef Medline

Homberg U, Hoskins SG, Hildebrand JG (1995) Distribution of acetylcholinesterase activity in the deutocerebrum of the sphinx moth Manduca sexta. Cell Tissue Res 279:249-259. CrossRef Medline

Huang J, Zhang W, Qiao W, Hu A, Wang Z (2010) Functional connectivity and selective odor responses of excitatory local interneurons in Drosophila antennal lobe. Neuron 67:1021-1033. CrossRef Medline

Husch A, Paehler M, Fusca D, Paeger L, Kloppenburg P (2009a) Calcium current diversity in physiologically different local interneuron types of the antennal lobe. J Neurosci 29:716-726. CrossRef Medline

Husch A, Paehler M, Fusca D, Paeger L, Kloppenburg P (2009b) Distinct electrophysiological properties in subtypes of nonspiking olfactory local interneurons correlate with their cell type-specific $\mathrm{Ca}^{2+}$ current profiles. J Neurophysiol 102:2834-2845. CrossRef Medline

Krofczik S, Menzel R, Nawrot MP (2009) Rapid odor processing in the honeybee antennal lobe network. Front Comput Neurosci 2:9. CrossRef Medline

Kuebler LS, Olsson SB, Weniger R, Hansson BS (2011) Neuronal processing of complex mixtures establishes a unique odor representation in the moth antennal lobe. Front Neural Circuits 5:7. CrossRef Medline

Leitch B, Laurent G (1996) GABAergic synapses in the antennal lobe and mushroom body of the locust olfactory system. J Comp Neurol 372:487514. CrossRef Medline

Lemon W, Getz W (1997) Temporal resolution of general odor pulses by olfactory sensory neurons in American cockroaches. J Exp Biol 200:18091819. Medline

Lemon WC, Getz WM (1998) Responses of cockroach antennal lobe projection neurons to pulsatile olfactory stimuli. Ann N Y Acad Sci 855:517520. CrossRef Medline

Lemon WC, Getz WM (2000) Rate code input produces temporal code output from cockroach antennal lobes. Biosystems 58:151-158. CrossRef Medline

Linster C, Smith BH (1997) A computational model of the response of honey bee antennal lobe circuitry to odor mixtures: overshadowing, blocking and unblocking can arise from lateral inhibition. Behav Brain Res 87:1-14. CrossRef Medline

Linster C, Sachse S, Galizia CG (2005) Computational modeling suggests that response properties rather than spatial position determine connectivity between olfactory glomeruli. J Neurophysiol 93:3410-3417. CrossRef Medline

Liu WW, Wilson RI (2013) Glutamate is an inhibitory neurotransmitter in the Drosophila olfactory system. Proc Natl Acad Sci U S A 110:1029410299. CrossRef Medline

MacLeod K, Laurent G (1996) Distinct mechanisms for synchronization and temporal patterning of odor-encoding neural assemblies. Science 274:976-979. CrossRef Medline

Malun D (1991a) Synaptic relationships between GABA-immunoreactive neurons and an identified uniglomerular projection neuron in the antennal lobe of Periplaneta americana: a double-labeling electron microscopic study. Histochemistry 96:197-207. CrossRef Medline

Malun D (1991b) Inventory and distribution of synapses of identified uniglomerular projection neurons in the antennal lobe of Periplaneta americana. J Comp Neurol 305:348-360. CrossRef Medline

Malun D, Waldow U, Kraus D, Boeckh J (1993) Connections between the deutocerebrum and the protocerebrum, and neuroanatomy of several classes of deutocerebral projection neurons in the brain of male Periplaneta americana. J Comp Neurol 329:143-162. CrossRef Medline

Neupert S, Fusca D, Schachtner J, Kloppenburg P, Predel R (2012) Toward a single-cell-based analysis of neuropeptide expression in Periplaneta americana antennal lobe neurons. J Comp Neurol 520:694-716. CrossRef Medline

Nowotny T, Stierle JS, Galizia CG, Szyszka P (2013) Data-driven honeybee antennal lobe model suggests how stimulus-onset asynchrony can aid odour segregation. Brain Res 1536:119-134. CrossRef Medline 
Olsen SR, Wilson RI (2008) Lateral presynaptic inhibition mediates gain control in an olfactory circuit. Nature 452:956-960. CrossRef Medline

Pippow A, Husch A, Pouzat C, Kloppenburg P (2009) Differences of $\mathrm{Ca}^{2+}$ handling properties in identified central olfactory neurons of the antennal lobe. Cell Calcium 46:87-98. CrossRef Medline

Sachse S, Galizia CG (2002) Role of inhibition for temporal and spatial odor representation in olfactory output neurons: a calcium imaging study. J Neurophysiol 87:1106-1117. Medline

Schmuker M, Yamagata N, Nawrot MP, Menzel R (2011) Parallel representation of stimulus identity and intensity in a dual pathway model inspired by the olfactory system of the honeybee. Front Neuroeng 4:17. CrossRef Medline

Schmuker M, Pfeil T, Nawrot MP (2014) A neuromorphic network for generic multivariate data classification. Proc Natl Acad Sci U S A 111:20812086. CrossRef Medline

Seki Y, Rybak J, Wicher D, Sachse S, Hansson BS (2010) Physiological and morphological characterization of local interneurons in the Drosophila antennal lobe. J Neurophysiol 104:1007-1019. CrossRef Medline

Strausfeld NJ, Li Y (1999) Organization of olfactory and multimodal affer- ent neurons supplying the calyx and pedunculus of the cockroach mushroom bodies. J Comp Neurol 409:603-625. CrossRef Medline

Tolbert LP, Hildebrand JG (1981) Organization and synaptic ultrastructure of glomeruli in the antennal lobes of the moth Manduca sexta: a study using thin sections and freeze fracture. Proc R Soc Lond B 213:279-301. CrossRef

Waldrop B, Hildebrand JG (1989) Physiology and pharmacology of acetylcholinergic responses of interneurons in the antennal lobes of the moth Manduca sexta. J Comp Physiol A 164:433-441. Medline

Wilson RI, Laurent G (2005) Role of GABAergic inhibition in shaping odorevoked spatiotemporal patterns in the Drosophila antennal lobe. J Neurosci 25:9069-9079. CrossRef Medline

Wilson RI, Mainen ZF (2006) Early evens in olfactory processing. Annu Rev Neurosci 29:163-201. CrossRef Medline

Wilson RI, Turner GC, Laurent G (2004) Transformation of olfactory representations in the Drosophila antennal lobe. Science 303:366-370. CrossRef Medline

Yaksi E, Wilson RI (2010) Electrical coupling between olfactory glomeruli. Neuron 67:1034-1047. CrossRef Medline 